\title{
Building bone is best in glucocorticoid-induced osteoporosis
}

In a randomized, comparator-controlled, phase III trial in men with glucocorticoidinduced osteoporosis (GIO), Glüer et al. found the bone-forming agent teriparatide to be more efficacious than the antiresorptive agent risedronate.

As glucocorticoids potently inhibit osteoblast activity, Glüer and co-workers hypothesized that bone-forming therapies would have greater therapeutic benefit in GIO than agents that abrogate bone resorption. To test this theory, they treated men who had taken glucocorticoids for $\geq 3$ months and had areal bone mineral density (BMD) T-scores $\leq-1.5$ SDs with teriparatide ( $20 \mu \mathrm{g}$ daily; $n=45)$ or risedronate ( $35 \mathrm{mg}$ weekly; $n=47$ ).

At 18 months follow-up, BMDs assessed by dual X-ray absorptiometry, quantitative $\mathrm{CT}$ (qCT) and high-resolution qCT (HRqCT) were increased for both treatment groups; however, substantially greater effects were generally seen after teriparatide treatment. For example, qCTderived spine trabecular BMD increased
$16.3 \%$ and $3.8 \%$ in the teriparatide and risedronate groups, respectively.

HRqCT analysis of bone microstructure revealed improvements in multiple variables for both teriparatide and risedronate treatment groups. Again, the effects were larger after teriparatide treatment.

\section{4 ...teriparatide had increased efficacy over risedronate... 77}

"Bone microstructure is an important predictor of bone strength independent of BMD or bone mass, and HRqCT techniques lend themselves to direct modelling of bone strength, which is an important determinant of fracture risk," explains Glüer. "Taken together, the improvements in both the cortical and trabecular compartments led to substantial increases in bone strength, under a variety of simulated loading conditions." Once again, teriparatide had increased efficacy over risedronate; for example, normalized strength in axial compression was increase by $26.2 \%$ and $5.8 \%$ in the teriparatide and risedronate groups, respectively. Interesting in this regard was the observation of 11 fractures in five patients treated with risedronate, but no fractures in the teriparatide group.

"This is the first study to demonstrate different responses of microstructural measures when comparing two therapies with fundamentally different modes of action, addition of bone matrix versus strengthening of existing bone," says Glüer. "Our ultimate goal is the development of a validated HRqCT-based surrogate marker for bone strength, and thus fracture risk."

David Killock

Original article Glüer, C. C. et al. Comparative effects of teriparatide and risedronate in glucocorticoid-induced osteoporosis in men: 18-month results of the EuroGIOPs trial. J. Bone Miner. Res. doi:10.1002/jbmr.1870 